\title{
Modeling the Evolution of Resistance in Cotton Bollworm to Concurrently Planted Bt Cotton and Bt Maize in China
}

\section{Wenhui Wang}

Hubei University

\section{Feng Xu}

Hubei University

Yunxin Huang ( $\nabla$ y.huang@hubu.edu.cn )

Hubei University https://orcid.org/0000-0002-8950-6512

\section{Hongqiang Feng}

Hebei Academy of Agriculture Science

\section{Peng Wan}

Hubei Academy of Agricultural Sciences

\section{Research article}

Keywords: Bt maize, Bt cotton, Cotton bollworm, Time to resistance, Model prediction

Posted Date: March 3rd, 2021

DOI: https://doi.org/10.21203/rs.3.rs-257699/v1

License: (9) This work is licensed under a Creative Commons Attribution 4.0 International License. Read Full License

Version of Record: A version of this preprint was published at Ecological Modelling on May 1st, 2022. See the published version at https://doi.org/10.1016/j.ecolmodel.2022.109912. 
1 Modeling the evolution of resistance in cotton bollworm to concurrently planted

2 Bt cotton and Bt maize in China

3

4

5

6

7

8

(1) 19 21 2
Wenhui Wang ${ }^{\mathrm{a}}$, Feng Xu ${ }^{\mathrm{a}}$, Yunxin Huanga, ${ }^{\mathrm{a},}$, Hongqiang Feng ${ }^{\mathrm{b}}$, Peng Wan ${ }^{\mathrm{c}}$

${ }^{a}$ School of Resource and Environmental Science, Hubei University, Wuhan, Hubei, 430062, PR China;

' Institute of Plant Protection, Henan Academy of Agricultural Science, Zhenzhou, Henan, 450002, PR China;

'Institute of Plant Protection \& Soil Science, Hubei Academy of Agricultural Science, Wuhan, Hubei, 450070, PR China;

*Corresponding author. E-mail: y.huang@hubu.edu.cn 8 0 3 
Background: Transgenic maize expressing toxins derived from the bacterium Bacillus thuringiensis (Bt) may be commercially planted in northern China where $\mathrm{Bt}$ cotton has been planted for more than two decades. While Bt maize brings additional benefits for insect control, it complicates the resistance management of cotton bollworm (CBW), Helicoverpa armigera (Lepidoptera, Noctuidae), a common target of Bt cotton and Bt maize.

Results: We developed population genetic models to assess the risk of resistance in CBW when $\mathrm{Bt}$ cotton and Bt maize are planted concurrently. Model simulations showed that when natural refuges are absent, the time to resistance (TTR) is less than 10 generations in the case of one-toxin $\mathrm{Bt}$ cotton and one-toxin $\mathrm{Bt}$ maize, but is more than 30 generations in the case of two-toxin $\mathrm{Bt}$ cotton and two-toxin Bt maize. The differences in the TTR between the two cases become greater as the proportion of natural refuge increases. Among the parameters we investigated, the fitness cost has a relatively smaller effect on the TTR, while the dominance of resistance and the proportion of natural refuge have a much greater effect.

Conclusions: We concluded that planting the first generation Bt cotton with Bt maize could significantly increase the risk of CBW resistance to $\mathrm{Bt}$ toxins as compared to planting a pyramid two-toxin Bt cotton. The strategies for reducing the risk of $\mathrm{CBW}$ resistance include replacing the one-toxin Bt cotton with a pyramid two-toxin Bt cotton, adopting a pyramid two-toxin Bt maize, and maintaining a sufficient proportion of natural refuges.

Keywords: Bt maize, Bt cotton, Cotton bollworm, Time to resistance, Model prediction 1 52 3 54 (1) . 


\section{Background}

Transgenic crops producing insecticidal proteins derived from Bacillus thuringiensis $(\mathrm{Bt})$ have become a major strategy to fight key insect pests in agriculture during the past two decades [1-4]. By 2018, transgenic crops were planted on more than 190 million hectares worldwide [5]. Among all transgenic crops, the majority is cotton, maize and soybean.

One of the main threats to the long-term use of $\mathrm{Bt}$ crops is that target pests may evolve resistance to Bt toxin. To date, field resistance has been observed in the target pests of both Bt cotton and Bt maize [6-11]. Resistance can be affected by various ecological and genetic factors [12]. Among them, the most important factor is excessive planting of Bt plants [13], but other factors such as insect susceptibility to the Bt toxin, dominance of resistance, and strategy of resistance management are also very important [14-17].

The refuge strategy is one of the general approaches to managing resistance. With this strategy, a proportion of non-Bt host is planted as refuge to maintain susceptible insect populations. Because abundant susceptible insects from refuge can compete for mating with rare resistant ones and produce heterozygous offspring that cannot survive on Bt plants, evolution of resistance is delayed [18]. The applications of the refuge strategies have been documented in literatures, in the cases of structured refuges [14], natural refuges [19,20], and seed mixture [4].

In China, Bt cotton is the only Bt crop that has been commercially planted so far [21]. One of the main targets of $\mathrm{Bt}$ cotton is cotton bollworm (CBW), Helicoverpa armigera (Lepidoptera, Noctuidae), a highly polyphagous insect pest that can feed on a number of different agricultural crops. In northern China, CBW has 4 generations per year. The host crops of CBW include cotton, maize, wheat, soybean, peanut, vegetables, and the availability of host crops vary among different generations [22]. For the first generation, wheat is the primary host crop when other major host crops like cotton and maize are absent. For the second through fourth generations, most of major host crops are available. An earlier study has shown that abundant non-cotton host crops in northern China served as natural refuges for CBW and contributed to delaying resistance of CBW to Bt cotton [20]. However, a more recent study has found that resistance to Bt cotton in CBW is accelerated by a dominant resistance allele [23].

Because maize has been one of the main categories of natural refuges for CBW in northern 
China so far, a practical question is what if the conventional maize is replaced with $\mathrm{Bt}$ maize in the region? Planting Bt maize will increase the proportion of Bt plants while decrease the proportion of natural refuge, so one can expect the risk of resistance to $\mathrm{Bt}$ to increase if the current composition of host plants is not changed. However, it is unknown how such an increase in the risk of resistance to $\mathrm{Bt}$ is affected by important factors associated with the $\mathrm{Bt}$ cotton and $\mathrm{Bt}$ maize varieties that have been or will be planting. These factors include the number and types of toxins contained in Bt cotton and Bt maize, the fitness parameters associated with Bt cotton and Bt maize, the mode of action in resistance to $\mathrm{Bt}$ cotton and $\mathrm{Bt}$ maize.

Simulation models perhaps are the best approach to addessing the questions above. Compared to experimental studies, simulation models have the advantages of reducing complexity and thus are widely used to assess the risk of insect resistance to Bt plants [24-30]. Simulation models have been used to assess the risk of Helicoverpa zea resistance to Bt cotton and Bt maize in the United States, where H. zea is a closely related species to CBW [31,32]. Similar models can be used to assess the risk of resistance to $\mathrm{Bt}$ cotton and $\mathrm{Bt}$ maize for $\mathrm{CBW}$ in northern China, but must take into account the fact that the Bt cotton and Bt maize varieties and their planting history in China are very different from those in the United States.

In this paper, a two-locus population genetic model is developed to analyze the resistance evolution of $\mathrm{CBW}$ to $\mathrm{Bt}$ cotton and $\mathrm{Bt}$ maize when the two species of $\mathrm{Bt}$ crops are planted concurrently. The model takes into account the actual Bt cotton variety and the existing resistance to Bt cotton. The questions to be addressed include: (1) What are the differences in the risk of resistance between an one-toxin $\mathrm{Bt}$ maize (Bt maize-1) and two-toxin Bt maize (Bt maize-2)? (2) How does the preexisting resistance to Bt cotton affect the risk of resistance when Bt cotton and Bt maize are planted together? (3) What are the key parameters that will impact on the risk of resistance?

\section{Results}

\section{The temporal patterns in the frequency of resistance alleles}

In the case of Bt cotton-1 \& Bt maize-1 where resistance is governed by a single locus, the only resistance allele $R_{1}$ increases in frequency rapidly over time (Fig. 1A). Because of fitness cost, the 
frequency of resistance allele goes to a level less than $100 \%$. The rapid increase in the frequency of resistance alleles is caused by a combination of dominant inheritance, high initial frequency and lack of natural refuge.

In the case of Bt cotton-1 \& Bt maize- 2 where resistance is governed by two loci, the temporal pattern in the frequency of $R_{1}$ is very different from that in the frequency of $R_{2}$ (Fig. 1B). The frequency of $R_{1}$ increases rapidly, similar to that in the single-locus case. Compared to that in the frequency of $R_{1}$, the frequency of $R_{2}$ increases much slower. It is worthy to note that the frequency of $R_{1}$ increases slower than that in the single-locus case even if all parameters related to Locus 1 are the same. Namely, there is an interaction between $R_{1}$ and $R_{2}$, which results in a slower increase in the frequency of $R_{1}$.

In the case of Bt cotton-2 \& Bt maize- 1 and of Bt cotton-2 \& Bt maize-2, where resistance is governed by two loci, similar interactions between $R_{1}$ and $R_{2}$ are observed (Fig. 1C\&D). Compared to that in the single-locus case, the frequencies of $R_{1}$ in all three two-locus cases increase slower.

\section{The impact of fitness cost}

To see how the fitness cost at Locus 1 affects resistance evolution, the time to resistance (TTR) is derived when the fitness cost at Locus 1 varies from 0 to 0.5 (Fig. 2). In all four cases, i.e. Bt cotton-1 \& Bt maize-1, Bt cotton-1 \& Bt maize-2, Bt cotton-2 \& Bt maize-1 and Bt cotton-2 \& Bt maize-2, the TTRs increase as the fitness cost increases. This is expected because fitness cost acts against resistance. However, in all four cases, the effect of the fitness cost at Locus 1 appears very limited. For example, in the case of Bt cotton-2 \& Bt maize-2, the TTR just increases from 31 to 32 generations when the fitness cost at Locus 1 varies from 0 to 0.5 . Among all four cases, for a fixed fitness cost the TTRs are much longer in the case of Bt cotton- $2 \&$ Bt maize- 2 than in the cases of Bt cotton-1 \& Bt maize-1, Bt cotton-1 \& Bt maize-2 and Bt cotton-2 \& Bt maize-1.

\section{The impact of dominance of resistance}

To see how the dominance at Locus 1 affects resistance evolution, the time to resistance (TTR) is derived when the dominance at Locus 1 varies from 0 to 0.8 (Fig. 3). In all four cases, i.e. Bt cotton-1 \& Bt maize-1, Bt cotton-1 \& Bt maize-2, Bt cotton-2 \& Bt maize-1 and Bt cotton-2 \& Bt maize-2, the TTRs decrease as the dominance increases. This is expected because a dominant 
resistance generally favors the spread of resistance alleles. In the first three cases, i.e. Bt cotton-1 \& Bt maize-1, Bt cotton-1 \& Bt maize-2, and Bt cotton-2 \& Bt maize-1, where there is either a one-toxin $\mathrm{Bt}$ cotton or a one-toxin $\mathrm{Bt}$ maize, the impact of dominance on TTR is relatively weaker. In the case of Bt cotton- 2 \& Bt maize-2, i.e. the case of two-toxin Bt cotton and two-toxin Bt maize, the effect of dominance is much stronger than in the first three cases. Among all four cases, for a fixed dominance the TTRs are much longer in the case of Bt cotton- 2 \& Bt maize-2 than in the cases of Bt cotton-1 \& Bt maize-1, Bt cotton-1 \& Bt maize-2 and Bt cotton-2 \& Bt maize-1.

\section{The impact of natural refuge}

To examine the impact of natural refuge on resistance, the time to resistance (TTR) is derived when the proportion of natural refuge varies from 0 to 0.6 (Fig. 4). In all four cases, i.e. Bt cotton-1 \& Bt maize-1, Bt cotton-1 \& Bt maize-2, Bt cotton-2 \& Bt maize-1 and Bt cotton-2 \& Bt maize-2, the TTRs increase as the proportion of natural refuge increases. This is expected because refuges delays resistance. For a fixed proportion of natural refuge there are large differences in the TTRs among the four cases. The larger the proportion of natural refuge, the larger the differences in TTRs. Among all four cases, for a fixed proportion of refuge the TTRs are much longer in the case of Bt cotton-2 \& Bt maize-2 than in the cases of Bt cotton-1 \& Bt maize-1, Bt cotton-1 \& Bt maize-2 and Bt cotton-2 \& Bt maize-1.

\section{Discussion}

$\mathrm{Bt}$ cotton is one of the earliest Bt crops that have been commercially planted in the world since 1996 [5]. While most of countries have replaced the first generation Bt cotton with newer generations [13,33], China has been planting the first generation Bt cotton expressing crylAc $[4,23]$. Our modeling results here showed that planting such a first generation Bt cotton together with Bt maize expressing similar Bt toxins could significantly increase the risk of cotton bollworm resistance to the two Bt crops as a whole.

One of the main reasons that planting the first generation $\mathrm{Bt}$ cotton together with $\mathrm{Bt}$ maize could increase the risk of cotton bollworm resistance was that cotton bollworm in China had evolved a dominant resistance to Bt cotton. A literature had shown that the degree of dominance for the resistance allele was as high as 0.79 [23]. Our simulation results here showed that such a 
highly dominant resistance could spread very fast as compared with a recessive or additive resistance.

Another reason that planting the first generation Bt cotton with Bt maize could increase the risk of cotton bollworm resistance was that the $\mathrm{Bt}$ maize and $\mathrm{Bt}$ cotton contain a similar Bt toxin. When the two Bt crops contain a similar Bt toxin, resistance is most likely governed by the same locus or loci [32]. In this case, the resistance to Bt maize is superimposed on that to Bt cotton and therefore evolves much faster than without the preexisting resistance to Bt cotton. Our simulation results confirmed the above scenario. In particular, our results showed that the high initial frequency of resistance could result in a rapid increase in the frequency of resistance when Bt maize is planted and the proportion of natural refuge is reduced.

Our results showed that planting a pyramid product of two-toxin Bt maize with the first generation Bt cotton could reduce the risk of resistance as compared with planting a single-toxin Bt maize. This is consistent with our previous work in a more general setting [34]. It is also generally consistent with the results in other literatures [35,36]. However, when the first generation $\mathrm{Bt}$ cotton is planted, the differences between the two-toxin $\mathrm{Bt}$ maize and one-toxin $\mathrm{Bt}$ maize are limited. This is because when the first generation Bt cotton is planted, the risk of resistance in the landscape is mainly determined by that in cotton fields, even when a two-toxin $\mathrm{Bt}$ maize reduces the risk of resistance in maize fields.

Our results showed that planting a two-toxin Bt maize with a two-toxin $\mathrm{Bt}$ cotton could substantially reduce the risk of resistance as compared with planting the first generation Bt cotton. When both two-toxin Bt cotton and Bt maize are planted, the risk of resistance in the landscape is determined by two resistance alleles and the risk of resistance in the landscape is low as long as one of the frequencies of the resistance alleles is low [41]. This is exactly the case when both two-toxin Bt maize and Bt cotton are planted. Therefore, planting a two-toxin Bt maize with a two-toxin Bt cotton could effectively counter the risk of resistance in CBW.

Literatures have shown that compared to block refuge, seed mixtures of $\mathrm{Bt}$ and non-Bt plants can generally accelerate resistance, by reducing the effective refuge size or increasing the effective dominance of resistance $[37,39]$. Our model simulations showed that this was also the case for $\mathrm{CBW}$ with cotton and maize seed mixture. However, the extent of acceleration in resistance depended on the rate of larval movement between plants. So far, researches about CBW 
larval movement between maize plants have been very limited. Future studies on this aspect are needed in order to more accurately predict the risk of resistance associated with seed mixture.

Our modeling results here have important implications for the strategy of resistance management in cotton bollworm when Bt cotton and Bt maize are planted together. Firstly, our results suggest that in order to reduce the risk of resistance, it is much better to plant a two-toxin $\mathrm{Bt}$ maize than to plant an one-toxin Bt maize. Secondly, if possible, the Bt maize should avoid having a similar $\mathrm{Bt}$ toxin to that in $\mathrm{Bt}$ cotton, which can reduce the effect of preexisting resistance on the evolution of resistance to Bt maize. Thirdly, for the very best, the Bt cotton should be replaced with a two-toxin one. A pyramid two-toxin Bt cotton not only reduces the risk of resistance to the $\mathrm{Bt}$ cotton itself but also that to $\mathrm{Bt}$ maize.

Because our main aims here were to give a qualitative evaluation rather than a quantitative prediction for the risk of resistance in cotton bollworm when Bt cotton and Bt maize planted concurrently, only a simple model was used. In order to give a more accurate, quantitative prediction, the model needs to extend to include other complex factors. Those factors include the population dynamics [22], spatial structure [27], and the composition and distribution of refuges $[31,35,38]$. In addition to including those factors, model parameters must also be accurately estimated [32]. While our model here did not include all of those factors, it provided a basis for including them and giving a quantitative prediction for the risk of resistance in cotton bollworm in the future.

\section{Conclusions}

In northern China, planting the first generation Bt cotton with Bt maize could significantly increase the risk of $\mathrm{CBW}$ resistance to $\mathrm{Bt}$ toxins as compared to planting a pyramid two-toxin $\mathrm{Bt}$ cotton. The risk is the highest when both one-toxin Bt cotton and one-toxin Bt maize are planted and lowest when both two-toxin Bt cotton and two-toxin Bt maize are planted. The strategies to reducing the risk of $\mathrm{CBW}$ resistance include replacing the currently planted one-toxin $\mathrm{Bt}$ cotton with a pyramid two-toxin $\mathrm{Bt}$ cotton, adopting a pyramid two-toxin $\mathrm{Bt}$ maize, and maintaining a sufficient proportion of natural refuges. 
A population genetic model was developed to analyze the adaptation of $\mathrm{CBW}$ to $\mathrm{Bt}$ cotton and $\mathrm{Bt}$ maize when the two types of Bt crops are planted together in northern China. In the study area, CBW has 4 generations per year [20,22]. In the first generation, the primary host crop is wheat when cotton and maize are absent. This means there is no selection for resistance to $\mathrm{Bt}$ in the first generation. For this reason, we only modeled three generations per year. For simplicity, we did not distinguish differences among generations and considered all model parameters as the averages across the three generations. We modeled a maximum of 120 generations or 40 years.

\section{The effective proportions of host crops}

We divided the host crops for CBW into three groups: cotton seed mixture, maize seed mixture and natural refuge (i.e. non-Bt host crops other than cotton and maize). We assumed that the effective proportions of the three groups are given, which are denoted by $P_{1}, P_{2}$, and $P_{\text {nat }}=1-$ $P_{1}-P_{2}$, respectively. Here the effective proportion is the proportion of planting area weighted by the relative effectiveness in producing susceptible insects [31]. Throughout this article, we referred to the "effective proportion" simply as "proportion" unless mentioned otherwise.

We assumed that the proportions of $\mathrm{Bt}$ and non-Bt plants in the cotton seed mixture are $P B t_{1}$ and 1- $P B t_{1}$, respectively, while the proportions of $\mathrm{Bt}$ and non-Bt plants in the maize seed mixture are $P B t_{2}$ and $1-P B t_{2}$, respectively.

\section{The Bt cotton and Bt maize products}

We considered two possible products for Bt cotton: a one-toxin product expressing crylAc or similar protein and a two-toxin product expressing $c r y 1 A c / c r y 2 A b$ or similar proteins, and denoted them by Bt cotton-1 and Bt cotton-2, respectively. We also considered two possible products for Bt maize: a one-toxin product expressing crylAb or similar protein and a two-toxin product expressing cry $1 \mathrm{Ab} / \mathrm{cry} 2 \mathrm{Aj}$ or similar proteins, and denoted them by Bt maize-1 and Bt maize-2, respectively. There are totally four combinations of Bt cotton and Bt maize: "Bt cotton-1 \& Bt maize-1", "Bt cotton-1 \& Bt maize-2", "Bt cotton-2 \& Bt maize-1" and "Bt cotton-2 \& Bt maize-2". 
We developed a general two-Bt-crop two-locus population genetic model to cover the four combinations of Bt cotton and Bt maize mentioned above. In the case of Bt cotton-1 \& Bt maize-1, we assumed that the Bt-resistance is governed by a single-locus with two alleles because Bt cotton-1 and Bt maize-2 express similar Bt proteins. In this case, a single-locus model is sufficient, which can be achieved by setting no selection at the second locus in the two-locus model. In the cases of "Bt cotton-1 \& Bt maize-2", "Bt cotton-2 \& Bt maize-1" and "Bt cotton-2 \& Bt maize-2", we assumed that the Bt-resistance is governed by two independently segregated loci with two alleles at each locus because Bt cotton-2 and Bt maize-2 share similar Bt proteins. Because a single-locus model is a special case of the two-locus model, we only described the two-locus model as follows.

The two-locus model is a discrete-time, frequency-dependent one in which the frequencies of genotypes are tracked from generation to generation. In the model, there are a total of nine genotypes. The key components of the model are the fitness functions on cotton seed mixture, maize seed mixture, and natural refuge, which, for convenience of expression, are denoted by $W_{\mathrm{M} 1}$, $W_{\mathrm{M} 2}$ and $W_{\mathrm{N}}$, respectively.

Following [39], we divided the entire period of CBW larvae into two stages and assumed that movement between plants occurs only when a larva completes the development of the first stage. Suppose that the movement from a Bt plant to a non-Bt plant or from a non-Bt plant to a Bt plant is completely random and that the probability of larval movement between plants is the same on cotton and maize plants $(m)$, then for any genotype $G$, we have

$$
\begin{gathered}
W_{M 1}(g)=P_{1, T T} \cdot W_{B 1}(G)+P_{1, N N} \cdot W_{N}(G)+P_{1, T N} \cdot\left[W_{B 1}(G)\right]^{q} \cdot\left[W_{N}(G)\right]^{1-q}+P_{1, N T} \cdot \\
{\left[W_{N}(G)\right]^{q} \cdot\left[W_{B 1}(G)\right]^{1-q}} \\
W_{M 2}(g)=P_{2, T T} \cdot W_{B 2}(G)+P_{2, N N} \cdot W_{N}(G)+P_{2, T N} \cdot\left[W_{B 2}(G)\right]^{q} \cdot\left[W_{N}(G)\right]^{1-q}+P_{2, N T} \cdot \\
{\left[W_{N}(G)\right]^{q} \cdot\left[W_{B 2}(G)\right]^{1-q}}
\end{gathered}
$$

Where $W_{\mathrm{B} 1}(G), W_{\mathrm{B} 2}(G)$ and $W_{\mathrm{N}}(G$ represent the fitnesses of genotype $\mathrm{G}$ on $\mathrm{Bt}$ cotton, $\mathrm{Bt}$ maize and any non-Bt plants, respectively. The parameter $0<\mathrm{q}<1$ designates the distribution of fitness over the two larval stages. Throughout the paper, we set $q=0.5$.

$P_{1, T T}, P_{1, N N}, P_{1, T N}$, and $P_{1, N T}$ are the probabilities that a larva moves from $\mathrm{Bt}$ to $\mathrm{Bt}$, Non-Bt to Non-Bt, Bt to Non-Bt and Non-Bt to Bt cotton plants, respectively. These probabilities were 
calculated as follows.

$$
\begin{aligned}
& P_{1, T T}=P B t_{1} \cdot\left(m \cdot P B t_{1}+1-m\right), P_{1, N N}=\left(1-P B t_{1}\right) \cdot\left[m \cdot\left(1-P B t_{1}\right)+1-m\right] \\
& P_{1, T N}=P B t_{1} \cdot m \cdot\left(1-P B t_{1}\right), P_{1, N T}=P_{1, T N}
\end{aligned}
$$

Where $P B t_{1}$ is the proportion of $\mathrm{Bt}$ in the cotton seed mixture.

Similarly, we can obtain the corresponding probabilities for larval movement between maize plants as follows.

$$
\begin{aligned}
& P_{2, T T}=P B t_{2} \cdot\left(m \cdot P B t_{2}+1-m\right), P_{2, N N}=\left(1-P B t_{2}\right) \cdot\left[m \cdot\left(1-P B t_{2}\right)+1-m\right] \\
& P_{2, T N}=P B t_{2} \cdot m \cdot\left(1-P B t_{2}\right), P_{2, N T}=P_{2, T N}
\end{aligned}
$$

Where $P B t_{2}$ is the proportion of $\mathrm{Bt}$ in the maize seed mixture.

We assumed that moths emerged from different host crops mate randomly. This assumption is reasonable because in the study area, host crops are planted by small-holder farmers and it is very common that different host crops are planted side by side in small fields [1]. With the assumption of random mating, the overall fitness of any two-locus genotype $G$ across cotton plants, maize plants and natural refuge is expressed by the following formula:

$$
\mathrm{W}(\mathrm{G})=P_{1} \times W_{M 1}(G)+P_{2} \times W_{M 2}(G)+\left(1-P_{1}-P_{2}\right) \times W_{N}(G)
$$

With the fitness function given above, the frequency of any genotype $G$ in the next generation, $f^{\prime}(G)$, is derived by the following recursive equation:

$$
f^{\prime}(\mathrm{G})=[\mathrm{f}(\mathrm{G}) \times \mathrm{W}(G)] /\left[\sum_{X} f(X) \times \mathrm{W}(X)\right], \text { for any } \mathrm{G}
$$

Where $\mathrm{f}(\mathrm{X})$ and $\mathrm{W}(\mathrm{X})$ are the frequency and fitness of the two-locus genotype $X$ in the present generation, respectively. Based on equation (1)-(6), the frequencies of all genotypes can be tracked from generation to generation. Once the frequencies of genotypes are available, the frequency of a resistance allele is obtained by summing up the frequencies of all genotypes having the resistance allele.

\section{The model parameters}

\section{Host crop parameters}

We assumed that the ratio of the effective proportion of cotton to that of maize is fixed at $P_{1}: P_{2}=$ 0.64: 0.36 and that the effective proportion of natural refuge $\left(P_{\text {nat }}\right)$ varies from 0 to 0.6. This ratio of $0.64: 0.36$ was obtained based on the effective proportions of cotton, maize and natural refuge in the study area in 2016 , which are $0.27,0.15$, and 0.58 , respectively [23]. The proportion 
of $\mathrm{Bt}$ in cotton was fixed at 0.75 , i.e. $P B t_{1}=0.75$. This value was used because the transgenic cotton plants in China were $\mathrm{F}_{2}$ hybrids between $\mathrm{Bt}$ and conventional cotton varieties, in which about $75 \%$ of the seeds expresses crylAc [4]. The proportion of $\mathrm{Bt}$ in maize was fixed at 0.8 , i.e. $\mathrm{PBt}_{2}=0.8$. This value was recommended for insects that are intrinsically less susceptible to $\mathrm{Bt}$ proteins in the United States [40].

\section{Fitness parameters}

We assumed the fitness of a two-locus genotype is multiplicative with respect to the two loci. With this assumption, we only needed to specify the fitnesses of one-locus genotypes, that is those of $S_{j} S_{j}, S_{j} R_{j}, R_{j} R_{j}$, where $\mathrm{j}=1,2$ stands for loci 1 and 2, respectively. The fitnesses of one-locus genotypes can be further computed based on fitness cost $\left(c_{j}\right)$, dominance of fitness cost $\left(d_{j}\right)$, Bt-caused mortality to susceptible $\mathrm{CBW}\left(\mu_{i j}\right)$, dominance of resistance $\left(\mathrm{h}_{i j}\right)$, and incomplete resistance $\left(\sigma_{i j}\right)$ (Table 1). Because the $\mathrm{Bt}$ proteins in $\mathrm{Bt}$ cotton and $\mathrm{Bt}$ maize are similar, we assumed that the Bt-caused mortality, dominance of resistance and incomplete resistance are the same between $\mathrm{Bt}$ cotton and Bt maize.

The first category of fitness parameters that we need to specify is the fitness cost $\left(c_{j}\right)$ and dominance of fitness cost $\left(\mathrm{d}_{j}\right)$ for $\mathrm{j}=1,2$. Among them, $\mathrm{c}_{1}$ is the fitness cost of resistance to crylAc or $c r y 1 A b$, while $\mathrm{c}_{2}$ is the fitness cost of resistance to $\operatorname{cry} 2 A b$ or $\operatorname{cry} 2 A j$. Experimental results have showed that fitness cost of resistance to crylAc might be as large as 0.54 [23]. To be conservative, here we used a smaller value of 0.36 as the default but also studied the cases when this parameter varies between 0 and 0.5 . Namely, we considered $0 \leq c_{1} \leq 0.5$. Experimental studies have shown that there is no fitness cost to resistance to cry $2 A b[33,41]$. Therefore, we set $c_{2}=0$. For the dominance of fitness cost, we followed Jin et al. [23] and Mahon and Young [33] and set $d_{1}=d_{2}=0$. This means that there is no fitness cost to the heterozygous genotypes.

The second category of fitness parameters that we need to specify is the Bt-caused mortality to susceptible genotypes $\left(\mu_{i j}\right)$. For mortality caused by Bt cotton expressing $c r y 1 A c$, both a lower $(0.95 ;[14])$ and higher value $(1 ;[20,23])$ were used in literature. To be conservative, we used the lower value 0.95 as the mortality to susceptible genotype caused by Bt plants expressing $c r y 1 A c$ or cryl $A b$, i.e. $\mu_{11}=\mu_{21}=0.95$. For mortality caused by Bt plants expressing $\operatorname{cry} 2 A b$ or $c r y 2 A j$, we do not have specific experimental data. However, we have experimental data for the mortality caused by $\mathrm{Bt}$ maize expressing cry $1 A b+c r y 2 A j$, which is roughly 0.99 [42]. Based on this 
experimental result and the mortality associated with $c r y l A b$ alone, we derived the mortality associated with $c r y 2 A j$ to be 0.8 . Therefore, we assumed that the mortality associated with $c r y 2 A b$ or $\operatorname{cry} 2 \mathrm{Aj}$ is 0.8 , i.e. $\mu_{21}=\mu_{22}=0.8$.

For the dominance of resistance, Jin et al. found that resistance to Bt cotton expressing $c r y l A c$ was dominant and that the degree of dominance was as high as 0.79 [23]. We followed this result and assumed that the dominance of resistance to $c r y l A c$ or $c r y l A b$ is 0.79 , i.e. $\mathrm{h}_{11}=\mathrm{h}_{21}=0.79$. For the incomplete resistance, Jin et al. used a value of 0.505 for Bt cotton expressing crylAc [23]. Based on this value, we assumed that the incomplete resistance to $c r y l A c$ or $c r y l A b$ is 0.505 , i.e. $\sigma_{11}=\sigma_{21}=0.505$. Because there was no experimental data to determine the dominance of resistance to $c r y 2 A b$ or $c r y 2 A j$ in China, we followed Edwards et al. [30] and used the value of 0.25 , i.e. $h_{12}=h_{22}=0.25$. Also because there was no experimental data to determine the value of incomplete resistance to $\operatorname{cry} 2 A b$ or $\operatorname{cry} 2 A j$, we adopted a conservative method ([32]) and assumed that the resistance is complete, i.e. $\sigma_{12}=\sigma_{22}=0$. All fitness parameters were summarized in Table 2.

\section{The larval movement parameter}

The probability of larval movement between plants depends on several factors, such as the insect's tendency and ability to move, the distance between plants and the growing stage of the plants. So far there is no evidence of significant CBW larval movement among plants. However, because larval movement generally increases the risk of resistance evolution [39], we adopted a conservative approach and considered a 10\% larval movement between plants. Namely, we assumed that the probability that a CBW larva moves from one plant to another during the entire larvae stage is 0.1 , i.e. $m=0.1$ (Table 2 ).

Initial frequencies of resistance alleles

A study showed that the frequency of resistance allele to Bt cotton in northern China was 0.1 in 2016 [23]. We used this value as the initial frequency of resistance allele associated with Locus 1. Because Bt maize has not yet planted in China, there is no way to determine the initial frequency of resistant allele empirically. Therefore, we used a theoretical value of 0.001 as the initial frequency of resistance allele associated with Locus 2 (see e.g. [27]).

\section{Time to resistance (TTR)}


385 We regarded the threshold of resistance risk as the frequency of a resistance allele reaches $50 \%$. In 386 the case of one-toxin Bt cotton or Bt maize where resistance is governed by a single locus, we 387 defined the "time to resistance" (TTR) as the time it takes for the frequency of the corresponding 388 single resistance allele to reach $50 \%$. In the case of two-toxin $\mathrm{Bt}$ cotton or $\mathrm{Bt}$ maize where resistance is governed by two loci, we defined the "time to resistance" (TTR) as the time it takes for the frequencies of both resistance alleles to reach $50 \%$.

391

\section{Computer programing}

The model was programmed with $\mathrm{C}++$ and ran at a personal computer.

\section{Declarations}

\section{Abbreviations}

TTR: Time to resistance

Bt maize-1: Bt maize containing only one $\mathrm{Bt}$ toxin

Bt maize-2: Bt maize containing two Bt toxins

\section{Acknowledgements}

405 We thank Dr. Kongming Wu for his comments on an early version of this paper.

\section{Authors' contributions}

408 W.W. and F.X. conducted the model analysis; Y.H. designed the study and wrote the article; H.F. 
and P.W. wrote the paper.

\section{Funding}

412

This work was supported by the National Natural Science Foundation of China (31670543). The funding agency has no role in design of the study, collection, analysis, and interpretation of the data, and writing of the manuscript.

415

Availability of data and materials

417

418

419

420

421

422

423

424

425

426

427 428

429

430

431

432

Ethics approval and consent to participate

Not applicable.

\section{Consent for publication}

Not applicable.

\section{Competing interests}

The authors declare that they have no competing interests.

\section{References}

1. Wu K, Lu Y, Feng H, Jiang Y, Zhao J. Suppression of cotton bollworm in multiple crops in China in areas with Bt toxin-containing cotton. Science. 2008;321:1676-1678. 
2. Hutchison WD, Burkness EC, Mitchell PD, Moon RD, Leslie TW, Fleischer SJ, et al. Areawide suppression of European maize borer with Bt maize reaps savings to non-Bt maize growers. Science. 2010;330: 222-225.

3. Huang Y, Wan P, Zhang H, Li Z, Wu K. Diminishing returns from increased percent bt cotton: the case of pink bollworm. PLoS One.2013;8(7):e68573.

4. Wan P, Xu D, Cong S, Jiang Y, Huang Y, Wang J, et al. Hybridizing transgenic Bt cotton with non-Bt cotton counters resistance in pink bollworm. Proc Natl Acad Sci USA. 2017;114(21):5413-5418

5. James, C. ISAAA Brief No. 54: Global Status of Commercialized Biotech/GM Crops: 2018. Ithaca NY: ISAAA; 2018.

6. Andow DA. The risk of resistance evolution in insects to transgenic insecticidal crops. Collection of Biosafety Reviews. 2008;4: 142-199.

7. Storer NP, Babcock JM, Schlenz M, Meade T, Thompson GD, Bing JW, et al. Discovery and characterization of field resistance to $\mathrm{Bt}$ maize: Spodoptera frugiperda (Lepidoptera: Noctuidae) in Puerto Rico. J Econ Entomol. 2010;103:1031-1038.

8. Bambawale OM, Tanwar PK, Sharma OP, Bhosle BB, Lavekar RC. Impact of refugia and integrated pest management on the performance of transgenic (Bacillus thuringiensis) cotton (Gossypium hirsutum). Indian J Agri Sci. 2010;80: 730-736.

9. Dhurua S, Gujar GT. Field-evolved resistance to Bt toxin CrylAc in the pink bollworm, Pectinophora gossypiella (Saunders) (Lepidoptera: Gelechiidae), from India. Pest Manag Sci. 2011;67:898-903.

10. Farias JR, Andow DA, Horikoshi RJ, Sorgatto RJ, Fresia P, dos Santos AC, et al. Field-evolved resistance to Cry1F maize by Spodoptera frugiperda (Lepidoptera: Noctuidae) in Brazil. Crop Protection. 2014;64:150-158.

11. Huang F, Qureshi JA, Meagher Jr. MR, Reisig DD, Head GP, Andow DA, et al. Cry1F resistance in fall armyworm Spodoptera frugiperda: single gene versus pyramided Bt maize. PLoS One. 2014;9(11): e112958.

12. Carrière Y, Crowder DW, Tabashnik BE. Evolutionary ecology of insect adaptation to Bt crops. Evol Appl. 2010;3: 561-573.

13. Tabashnik BT, Brévault T, Carrière Y. Insect resistance to Bt crops: lessons from the first billion 
acres. Nature Biotech. 2013;31:510-521

14. Tabashnik BE, Gassmann AJ, Crowder DW, Carrière Y. 2008. Insect resistance to Bt crops: evidence versus theory. Nature Biotech. 2008;26:199-202.

15. Zhang H, Wu S, Yang Y, Tabashnik BE, Wu Y. Non-recessive Bt toxin resistance conferred by an intracellular cadherin mutation in field-selected populations of cotton bollworm. PLoS ONE. 2012; 7: e53418.

16. Brévault T, Heuberger S, Zhang M, Ellers-Kirk C, Ni X, Masson L, et al. Potential shortfall of pyramided transgenic cotton for insect resistance management. Proc Natl Acad Sci USA. 2013;110:5806-5811.

17. Carrière Y, Fabrick JA, Tabashnik BE. Can pyramids and seed mixtures delay resistance to Bt crops? Trends in Biotechnology. 2016;34(4):291-302.

18. Gould F. Sustainability of transgenic insecticidal cultivars: integrating pest genetics and ecology. Annu. Rev. Entomol. 1998;43:701-726.

19. Zhang H, Yin W, Zhao J, Yang Y, Wu S, Tabashnik BE, et al. Early warning of cotton bollworm resistance associated with intensive planting of Bt cotton in China. PLoS ONE. 2011;6:e22874.

20. Jin L, Zhang HN, Lu YH, Yang YH, Wu KM, Tabashnik BT, et al. Large-scale test of the natural refuge strategy for delaying insect resistance to $\mathrm{Bt}$ crops. Nat. Biotech. 2015;33:169-174.

21. $\mathrm{Wu} \mathrm{K}$, Guo Y. The evolution of cotton pest management practices in China. Annu Rev Entomol. 2005;50: 31-52.

22. Feng H, Gould F, Huang Y, Jiang Y, Wu K. Modeling the population dynamics of cotton bollworm Helicoverpa armigera (Hübner) (Lepidoptera: Noctuidae) over a wide area in northern China. Ecological Modeling. 2010;221:1819-1830.

23. Jin L, Wang J, Guan F, Zhang JP, Yu S, Liu S. et al. Dominant point mutation in a tetraspanin gene associated with field-evolved resistance of cotton bollworm to transgenic Bt cotton. PNAS. 2018;115(46):11760-11765.

24. Peck SL, Gould F, Ellner SP. Spread of resistance in spatially-extended regions of transgenic cotton: implications for management of Heliothis virescens (Lepidoptera: Noctuidae). J. Econ. Entomol. 1999;92: 1-16. 
25. Caprio MA. Source-sink dynamics between transgenic and non-transgenic habitats and their role in the evolution of resistance. J. Econ. Entomol. 2001;94: 698-705.

26. Caprio MA, Faver MK, Hankins G. Evaluating the impacts of refuge width on source-sink dynamics between transgenic and non-transgenic cotton. Journal of Insect Science. 2004;4:3.

27. Ives AR, Glaum PR, Ziebarth NL, Andow DA. The evolution of resistance to two-toxin pyramid transgenic crops. Ecol. Appl. 2011;21(2):503-515.

28. Storer NP, Peck SL, Gould F, Van Duyn JW, Kennedy GG. Spatial processes in the evolution of resistance in Helicoverpa zea (Lepidoptera: Noctuidae) to Bt transgenic maize and cotton in a mixed agroecosystem: a biology-rich stochastic simulation model. J. Econ. Entomol. 2003;96, 156-172.

29. Caprio M, Parker CD, Schneider JC. Future fitness of female insect pests in temporally stable and unstable habitats and its impact on habitat utility as refuges for insect resistance management. J. Insect Sci. 2009;9: 44.

30. Edwards KT, Caprio MA, Allen KC, Musser FR. Risk assessment for Helicoverpa zea (Lepidoptera: Noctuidae) resistance on dualgene versus single-gene maize. J. Econ. Entomol. 2013;106: 382-392.

31. Gustafson DI, Head GP, Caprio MA. Modeling the impact of alternative hosts on Helicoverpa zea adaptation to Bollgard cotton. J. Econ. Entomol. 2006;99:2116-2124.

32. Pan Z, Onstad DW, Crain P, Crespo AL, Hutchison WD, Buntin D, et al. Evolution of resistance by Helicoverpa zea infesting insecticidal crops in the Southern United States. J. Econ. Entomol. 2016;109:821-831.

33. Mahon RJ, Young S. Selection experiments to assess fitness costs associated with cry $2 \mathrm{Ab}$ resistance in Helicoverpa armigera (Lepidoptera: Noctuidae). Journal of Economic Entomology. 2010;103(3):835-842.

34. Huang Y, Qin Y, Feng H, Wan P, Li Z. Modeling the evolution of insect resistance to one- and two-toxin Bt crops in spatially heterogeneous environments. Ecological Modeling. 2017;347:72-84.

35. Zhao JZ, Cao J, Collins HL. Bates SL. Roush RT, Earle ED, et al. Concurrent use of transgenic plants expressing a single and two Bacillus thuringiensis genes speeds insect adaptation to pyramided plants. Proc Natl Acad Sci USA. 2005;102(24): 8426-8430. 
36. Onstad DW, Meinke LJ. Modeling evolution of Diabrotica virgifera virgifera (Coleoptera: Chrysomelidae) to transgenic corn with two insecticidal traits. J. Econ. Entomol. 2010; 103:849-860.

37. Carrière Y, Fabrick JA, Tabashnik BE. Can pyramids and seed mixtures delay resistance to Bt crops? Trends in Biotechnology. 2016;34(4):291-302.

38. Li Y, Gao Y, Wu K. Function and effectiveness of natural refuge in IRM strategies for Bt crops. Current Opinion in Insect Science. 2017;21:1-6.

39. Mallet J, Porter P. Preventing insect adaptation to insect-resistant crops: Are seed mixtures or refugia the best strategy? Phil. Trans. R. Soc. Lond. B Biol. Sci. 1992;250: 165-169.

40. U.S.EPA. Biopesticides registration action document: Bacillus thuringiensis plant-incorporated protectants. U.S. EPA, Washington, D.C., USA; 2011.

41. Liu L, Gao M, Yang S, Liu S, Wu Y, Carrière Y, et al. Resistance to Bacillus thuringiensis toxin Cry2Ab and survival on single-toxin and pyramided cotton in cotton bollworm from China. Evolutionary Applications. 2017;10(2):170-179.

42. Chang $\mathrm{X}$, Wang W, Shen $\mathrm{Z}$, Ye G. Evaluation of transgenic cry1Ab/cry2Aj and cry1 Ab/vip3DA maize for its resistance to Helicoverpa armigera (Hübner), Spodoptera exigua (Hübner) and Prodenia litura (Fabricius). (In Chinese with English abstract). (Chinese) Journal of Plant Protection. 2016;43(6):951-957. 

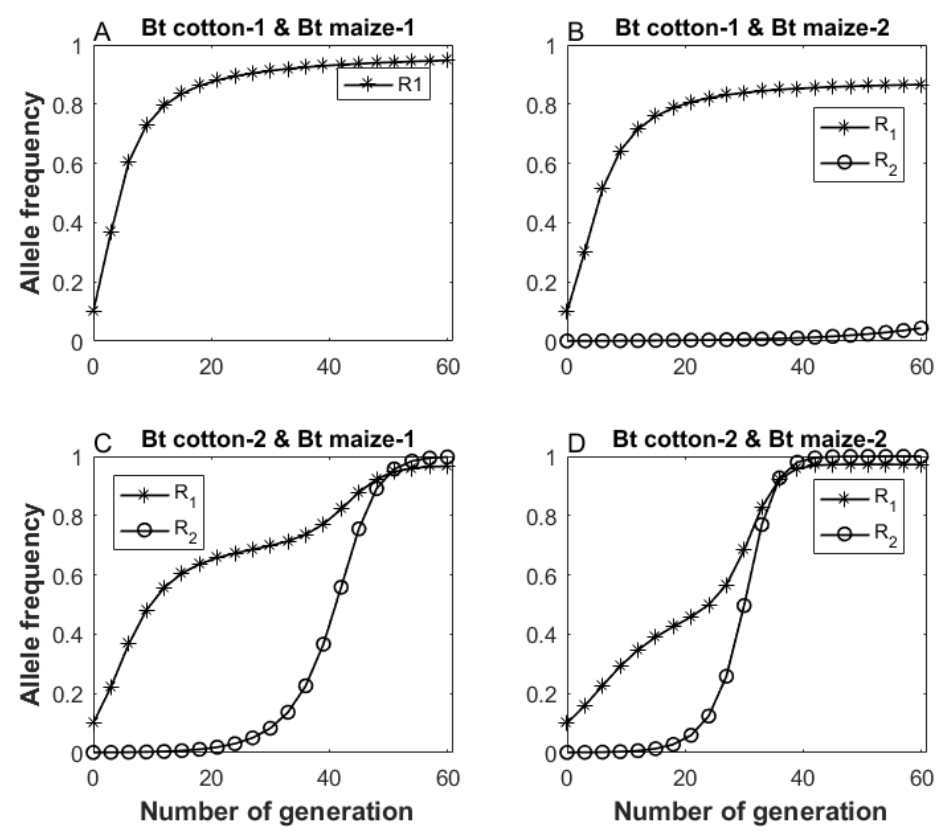

566 Figure 1 Temporal patterns in the frequency of resistance alleles. A. one-locus model for Bt cotton-1 \& Bt maize-1. B. two-locus model for Bt cotton-1 \& Bt maize-2. C. two-locus model for Bt cotton-2 \& Bt maize-1. D. two-locus model for Bt cotton-2 \& Bt maize-2. $R_{1}$ and $R_{2}$ represent the resistance alleles at loci 1 and 2 , respectively. In this figure, $P_{1}=0.64, P_{2}=0.36, P_{\text {nat }}=0$. The rest of parameters are set at default.

571 


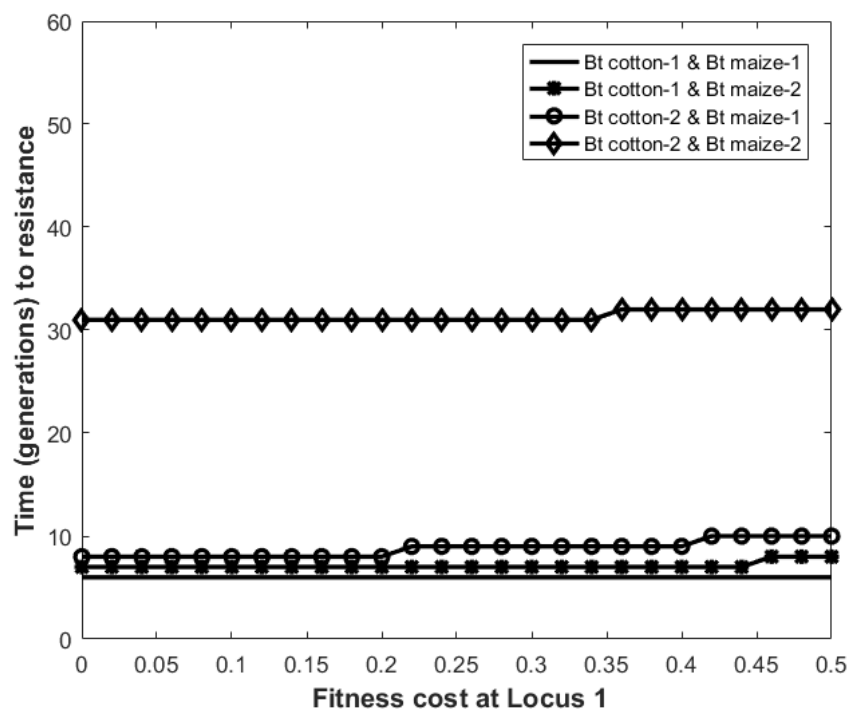

Figure 2 Time to resistance versus fitness cost at locus 1. The four lines with none, star, circle and diamond marks correspond to the cases of Bt cotton-1 \& Bt maize-1, Bt cotton-1 \& Bt maize-2, Bt cotton-2 \& Bt maize-1 and Bt cotton-2 \& Bt maize-2, respectively. The horizontal axis is the fitness cost at Locus $1\left(c_{1}\right)$ and the vertical axis is the time to resistance (TTR). In this figure, $P_{1}=0.64, P_{2}=0.36, P_{\text {nat }}=0$. The rest of parameters are set at default.

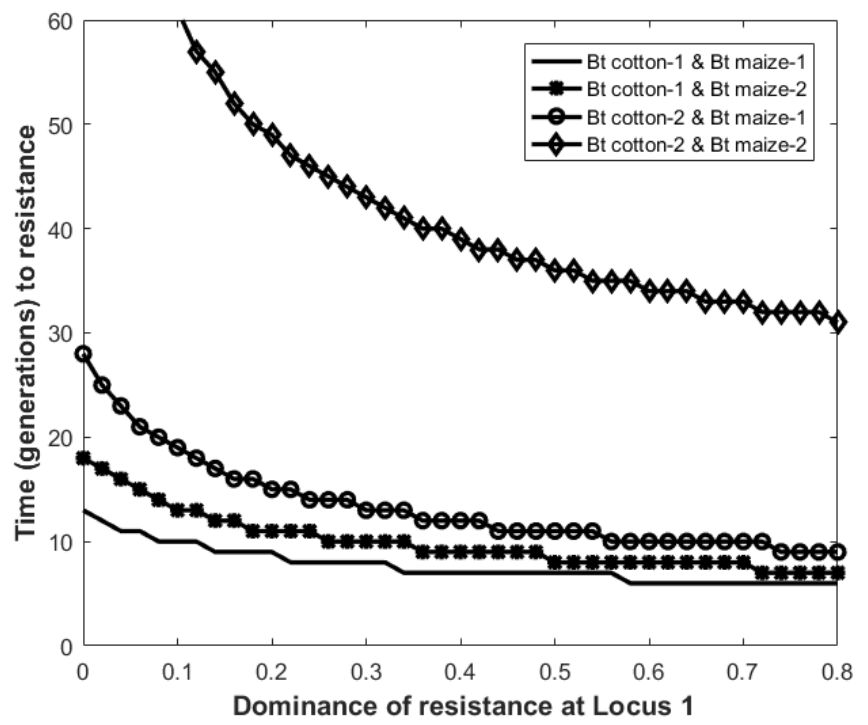

Figure 3 Time to resistance versus dominance of resistance at locus 1 . The four lines with none, star, circle and diamond marks correspond to the cases of Bt cotton- 1 \& Bt maize-1, Bt cotton-1 \& Bt maize-2, Bt cotton-2 \& Bt maize-1 and Bt cotton-2 \& Bt maize-2, respectively. The horizontal axis is the dominance of resistance at Locus $1\left(h_{11}\right)$ and the vertical axis is the time to resistance (TTR). In this figure, $P_{1}=0.64, P_{2}=0.36, P_{\text {nat }}=0$. The rest of parameters are set at default. 


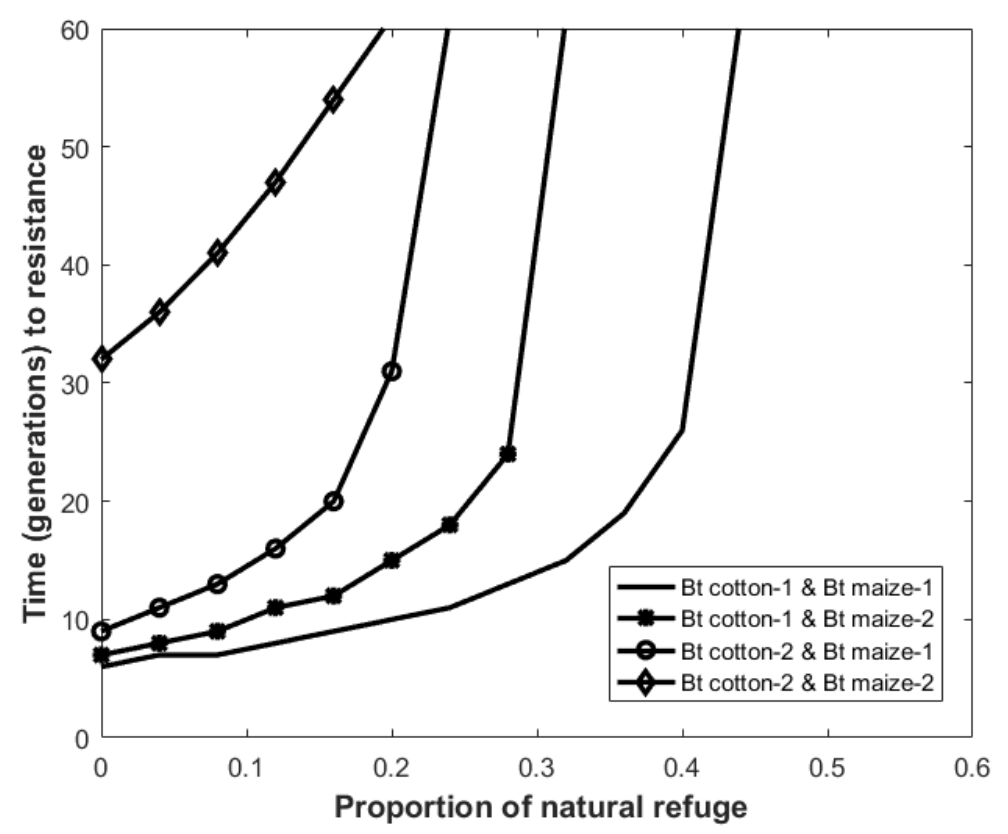

587

Figure 4 Time to resistance versus proportion of natural refuge. The four lines with none, star, circle and diamond marks correspond to the cases of Bt cotton- $1 \&$ Bt maize-1, Bt cotton-1 \& Bt maize-2, Bt cotton-2 \& Bt maize-1 and Bt cotton-2 \& Bt maize-2, respectively. The horizontal axis is the proportion of natural refuge $\left(P_{\text {nat }}\right)$ and the vertical axis is the time to resistance (TTR).

The rest of parameters are set at default.

Table 1 The formulae for fitness computation.

\begin{tabular}{clc}
\hline Notation & \multicolumn{1}{c}{ Meaning } & formula \\
\hline$W_{N}\left(S_{j} S_{j}\right)$ & Fitness of $S_{j} S_{j}$ on non-Bt plants $(\mathrm{j}=1,2)$ & 1 \\
$W_{N}\left(S_{j} R_{j}\right)$ & Fitness of $S_{j} R_{j}$ on non-Bt plants $(\mathrm{j}=1,2)$ & $1-d_{j} \cdot c_{j}$ \\
$W_{N}\left(R_{j} R_{j}\right)$ & Fitness of $R_{j} R_{j}$ on non-Bt plants $(\mathrm{j}=1,2)$ & $1-c_{j}$ \\
$W_{B 1}\left(S_{j} S_{j}\right)$ & Fitness of $S_{j} S_{j}$ on Bt cotton $(\mathrm{j}=1,2)$ & $1-\mu_{1 j}$ \\
$W_{B 1}\left(S_{j} R_{j}\right)$ & Fitness of $S_{j} R_{j}$ on Bt cotton $(\mathrm{j}=1,2)$ & $\left(1-\mu_{1 j}\right)+h_{1 j} \cdot\left(\mu_{1 j}-\sigma_{1 j}\right)$ \\
$W_{B 1}\left(R_{j} R_{j}\right)$ & Fitness of $R_{j} R_{j}$ on Bt cotton $(\mathrm{j}=1,2)$ & $1-\sigma_{1 j}$ \\
$W_{B 2}\left(S_{j} S_{j}\right)$ & Fitness of $S_{j} S_{j}$ on Bt maize $(\mathrm{j}=1,2)$ & $1-\mu_{2 j}$ \\
$W_{B 2}\left(S_{j} R_{j}\right)$ & Fitness of $S_{j} R_{j}$ on Bt maize $(\mathrm{j}=1,2)$ & $\left(1-\mu_{2 j}\right)+h_{2 j} \cdot\left(\mu_{2 j}-\sigma_{2 j}\right)$ \\
$W_{B 2}\left(R_{j} R_{j}\right)$ & Fitness of $R_{j} R_{j}$ on Bt maize $(\mathrm{j}=1,2)$ & $1-\sigma_{2 j}$ \\
\hline
\end{tabular}


Table 2 The notation, meaning and default value or range of parameters used in model

597 simulation.

\begin{tabular}{clcc}
\hline Notation & \multicolumn{1}{c}{ Meaning } & Default/range & Reference \\
\hline$p_{10}$ & Initial frequency of resistance allele at Locus 1 & 0.1 & {$[23]$} \\
$p_{20}$ & Initial frequency of resistance allele at Locus 2 & 0.001 & {$[27]$} \\
$m$ & Probability of larval movement between plants & 0.1 & here \\
& Mortality of $\mathrm{S}_{1} \mathrm{~S}_{1}$ caused by Bt cotton containing & 0.95 & {$[14,20,23]$} \\
$\mu_{11}$ & crylAc or cry $1 \mathrm{Ab}$ & & \\
& Mortality of $\mathrm{S}_{2} \mathrm{~S}_{2}$ caused by Bt cotton containing & 0.8 & {$[41]$} \\
$\mu_{12}$ & cry $2 A b$ or cry $2 A j$ & & {$[23]$} \\
$c_{1}$ & Fitness cost of $\mathrm{R}_{1} \mathrm{R}_{1}$ & 0.36 & {$[33,39]$} \\
$c_{2}$ & Fitness cost of $\mathrm{R}_{2} \mathrm{R}_{2}$ & 0 & {$[23,33]$} \\
$d_{j}$ & Dominance of fitness cost for $\mathrm{R}_{\mathrm{j}}(j=1,2)$ & 0 & {$[23]$} \\
$\sigma_{11}$ & Incomplete resistance of $\mathrm{R}_{1} \mathrm{R}_{1}$ on Bt cotton & 0.505 & {$[32]$} \\
$\sigma_{12}$ & Incomplete resistance of $\mathrm{R}_{2} \mathrm{R}_{2}$ on Bt cotton & 0 & {$[23]$} \\
$h_{11}$ & Dominance of resistance for $\mathrm{R}_{1}$ on Bt cotton & 0.79 & {$[30]$} \\
$h_{12}$ & Dominance of resistance for $\mathrm{R}_{2}$ on Bt cotton & 0.25 & \\
\hline
\end{tabular}
with Bt cotton: $\mu_{2 j}=\mu_{1 j}, \sigma_{2 j}=\sigma_{1 j}, h_{2 j}=h_{1 j}$, for $j=1,2$. 


\section{Figures}
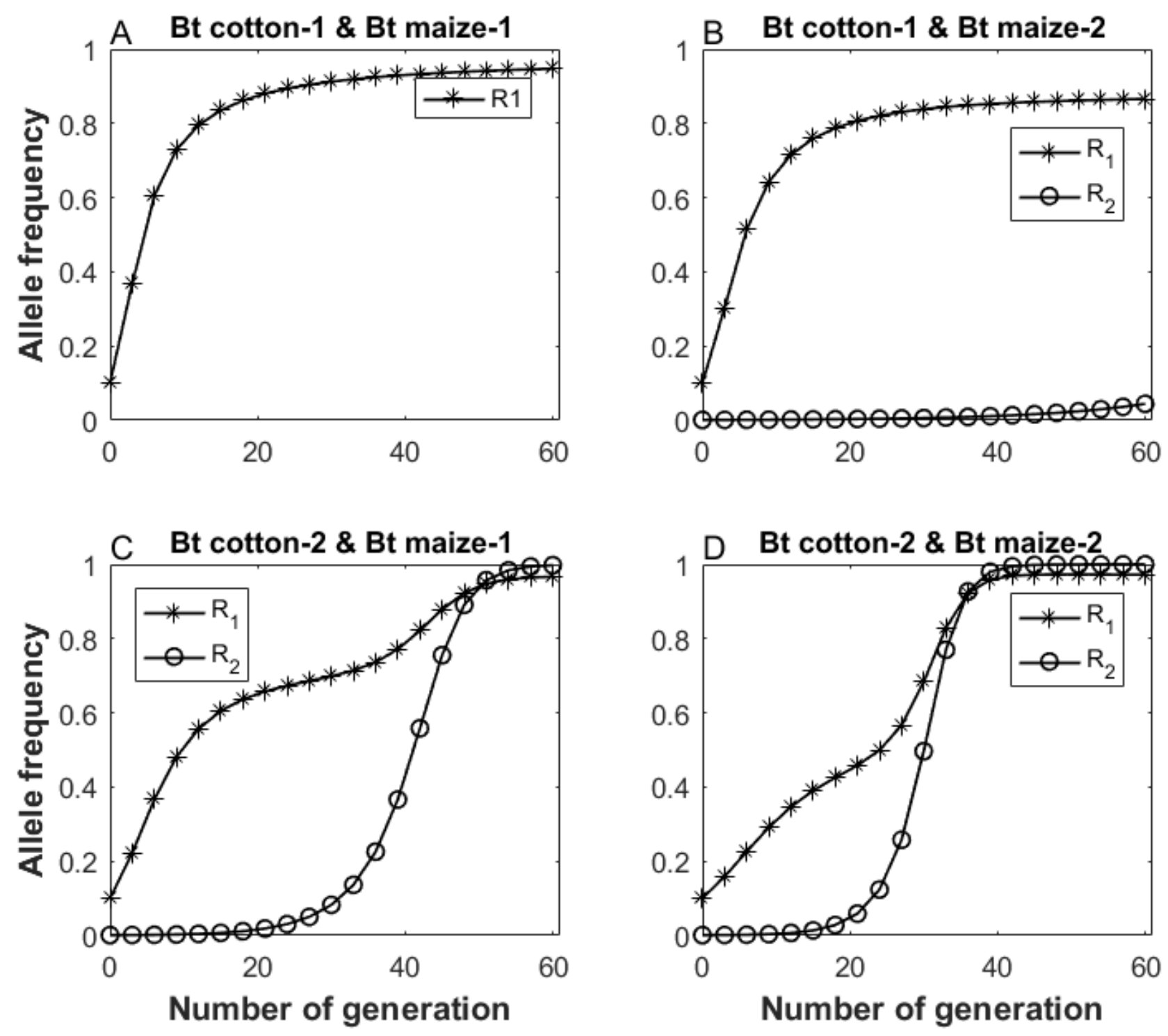

Figure 1

Temporal patterns in the frequency of resistance alleles. A. one-locus model for Bt cotton-1 \& Bt maize-1. B. two-locus model for Bt cotton-1 \& Bt maize-2. C. two-locus model for Bt cotton-2 \& Bt maize-1. D. twolocus model for Bt cotton-2 \& Bt maize-2. R1 and R2 represent the resistance alleles at loci 1 and 2 , respectively. In this figure, $\mathrm{P} 1=0.64, \mathrm{P} 2=0.36$, Pnat $=0$. The rest of parameters are set at default. 


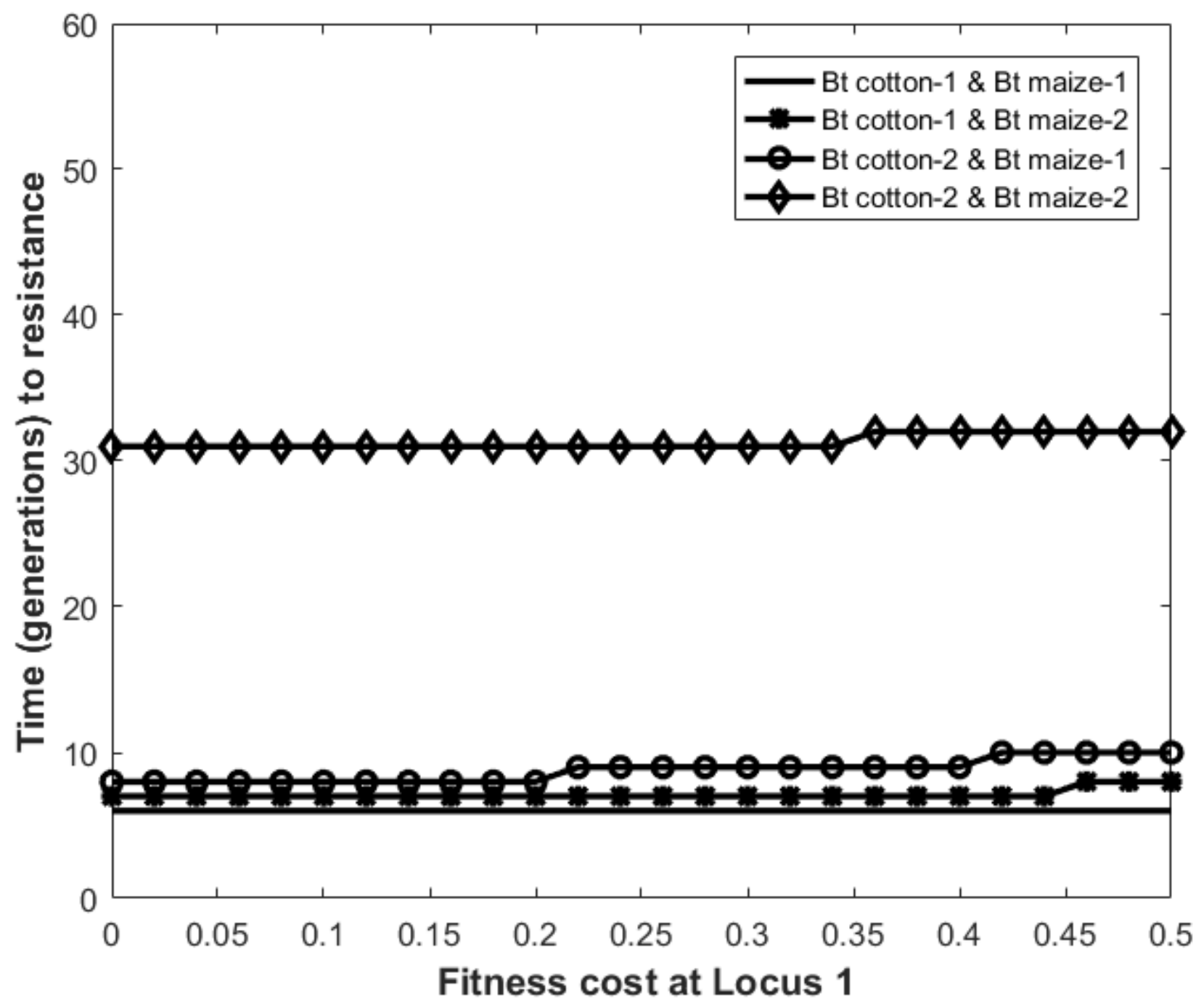

Figure 2

Time to resistance versus fitness cost at locus 1 . The four lines with none, star, circle and diamond marks correspond to the cases of Bt cotton-1 \& Bt maize-1, Bt cotton-1 \& Bt maize-2, Bt cotton-2 \& Bt maize-1 and Bt cotton-2 \& Bt maize-2, respectively. The horizontal axis is the fitness cost at Locus 1 (c1) and the vertical axis is the time to resistance (TTR). In this figure, $\mathrm{P} 1=0.64, \mathrm{P} 2=0.36$, Pnat $=0$. The rest of parameters are set at default. 


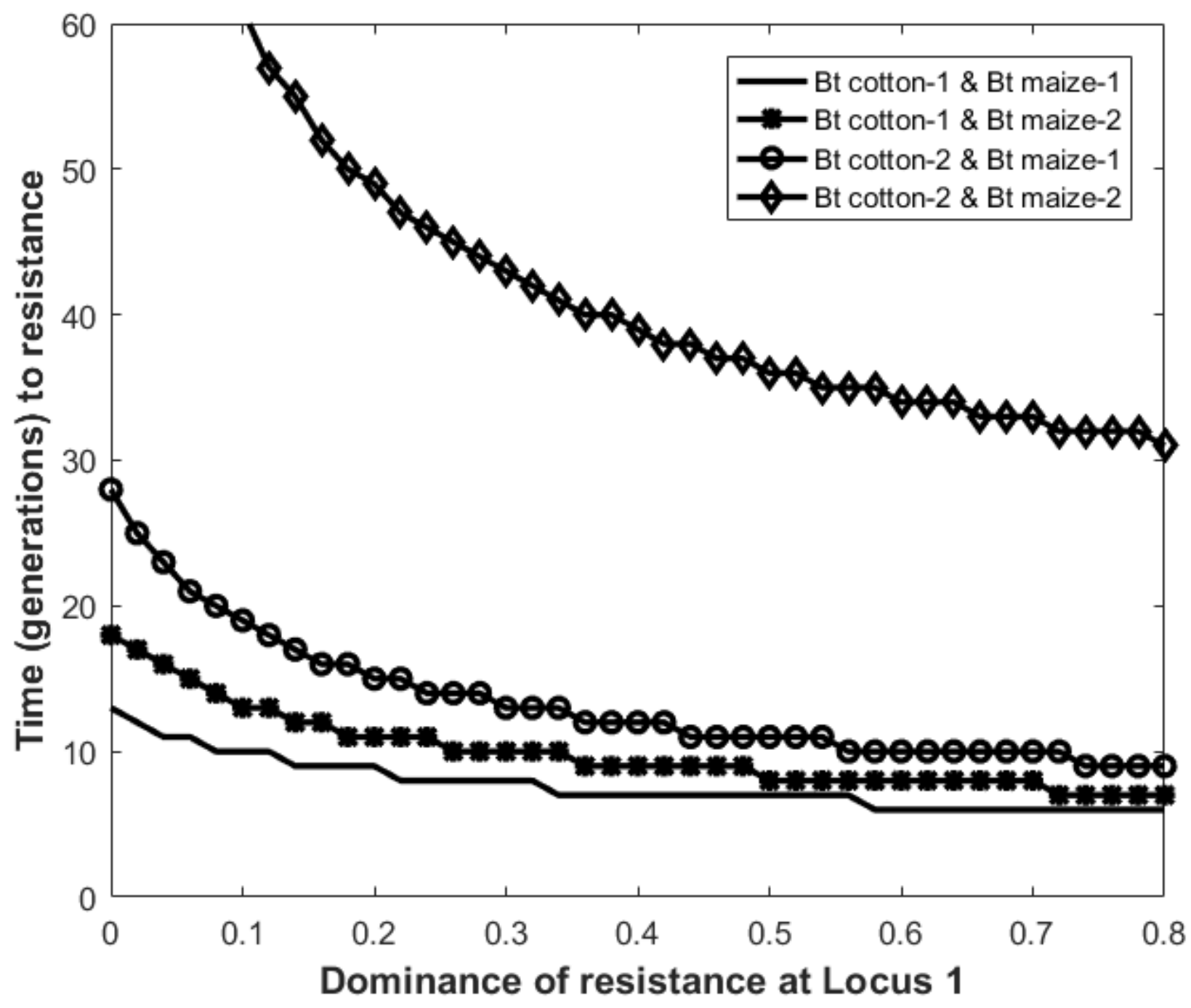

Figure 3

Time to resistance versus dominance of resistance at locus 1. The four lines with none, star, circle and diamond marks correspond to the cases of Bt cotton- 1 \& Bt maize-1, Bt cotton- 1 \& Bt maize-2, Bt cotton-2 \& Bt maize-1 and Bt cotton-2 \& Bt maize-2, respectively. The horizontal axis is the dominance of resistance at Locus 1 (h11) and the vertical axis is the time to resistance (TTR). In this figure, P1 $=0.64$, $\mathrm{P} 2=0.36$, Pnat $=0$. The rest of parameters are set at default. 


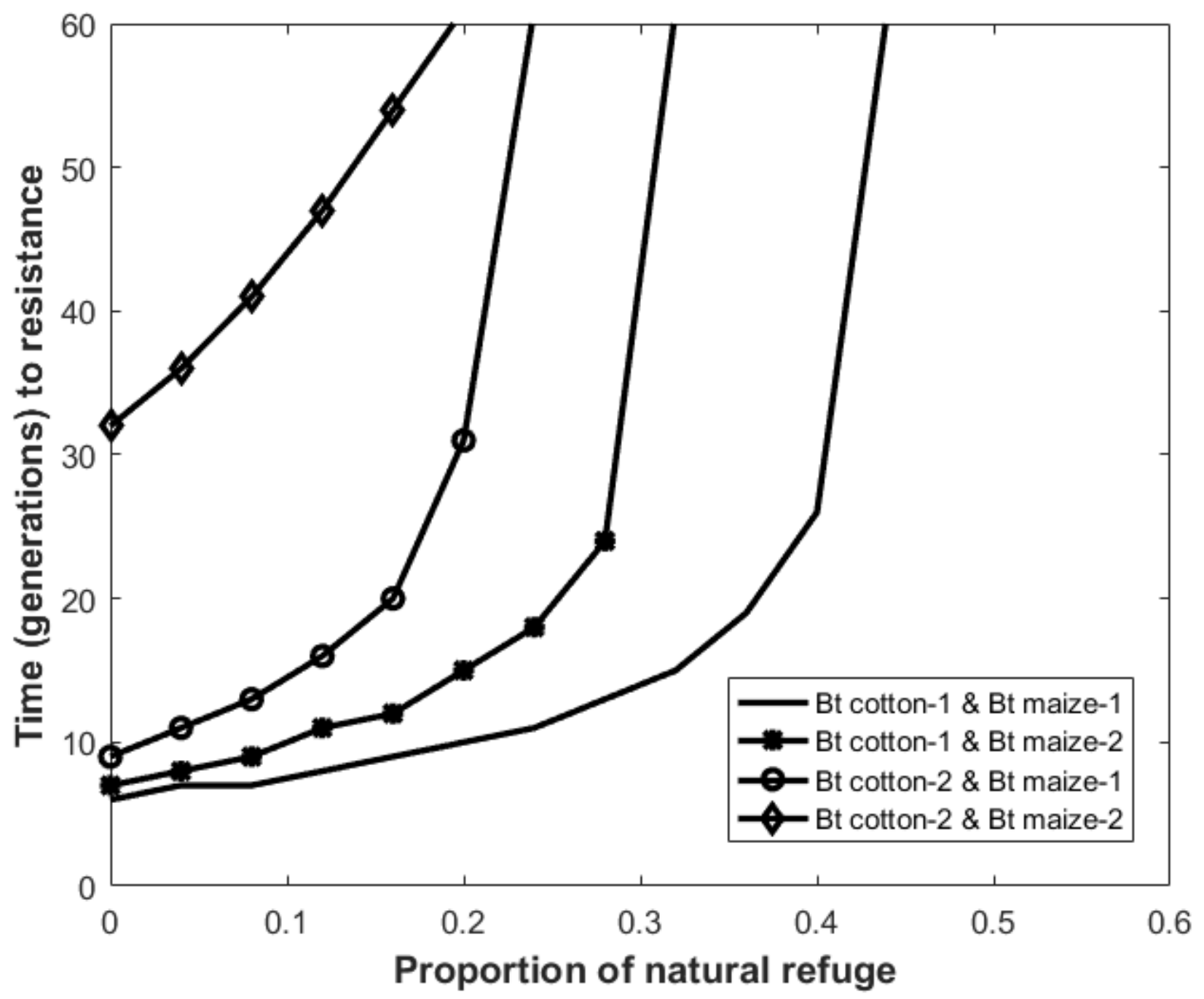

Figure 4

Time to resistance versus proportion of natural refuge. The four lines with none, star, circle and diamond marks correspond to the cases of Bt cotton-1 \& Bt maize-1, Bt cotton-1 \& Bt maize-2, Bt cotton-2 \& Bt maize-1 and Bt cotton-2 \& Bt maize-2, respectively. The horizontal axis is the proportion of natural refuge (Pnat) and the vertical axis is the time to resistance (TTR). The rest of parameters are set at default. 